Preprints of the

Max Planck Institute for

Research on Collective Goods

Bonn 2013/3

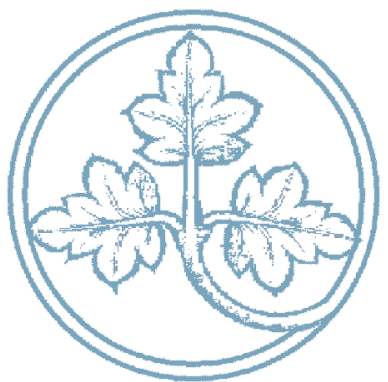

Bank Bonuses

and Bail-Outs

Hendrik Hakenes

Isabel Schnabel

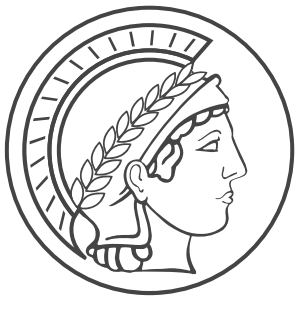




\title{
Bank Bonuses and Bail-Outs
}

\author{
Hendrik Hakenes / Isabel Schnabel
}

February 2013

Max Planck Institute for Research on Collective Goods, Kurt-Schumacher-Str. 10, D-53113 Bonn http://www.coll.mpg.de 


\title{
Bank Bonuses and Bail-Outs*
}

\author{
Hendrik Hakenes ${ }^{\dagger}$ \\ University of Bonn and MPI Bonn \\ Isabel Schnabel ${ }^{\ddagger}$ \\ Johannes Gutenberg University Mainz, CEPR, and MPI Bonn
}

\begin{abstract}
This paper shows that bonus contracts may arise endogenously as a response to agency problems within banks, and analyzes how compensation schemes change in reaction to anticipated bail-outs. If there is a risk-shifting problem, bail-out expectations lead to steeper bonus schemes and even more risk-taking. If there is an effort problem, the compensation scheme becomes flatter and effort decreases. If both types of agency problems are present, a sufficiently large increase in bailout perceptions makes it optimal for a welfare-maximizing regulator to impose caps on bank bonuses. In contrast, raising managers' liability can be counterproductive.
\end{abstract}

Keywords: Bonus payments; bank bail-outs; bank management compensation; risk-shifting; underinvestment; limited and unlimited liability.

JEL-Classification: G21, G28, M52, J33.

\footnotetext{
${ }^{*}$ We thank Thorsten Beck, Jakob de Haan, and Robert DeYoung (the Editors), our discussants Uwe Bloos, Fabio Castiglionesi, Christian Eufinger, and Werner Neus, as well as Christoph Engel, Guido Friebel, Charles Goodhart, Alexander Morell, Javier Suarez, Wolf Wagner, one anonymous referee, seminar participants at the Universities of Frankfurt and Hannover, and conference participants of the Annual Meeting of the German Economic Association, the German Economic Association for Business Administration (GEABA), the German Finance Association (DGF), as well as the 1st Research Workshop in Financial Economics in Mainz and the Post-Crisis Banking Conference in Amsterdam for useful comments and suggestions.

${ }^{\dagger}$ Finance Department, University of Bonn, Adenauerallee 24-42, 53113 Bonn, Germany, hakenes@uni-bonn.de.

${ }^{\ddagger}$ Gutenberg School of Management and Economics, Johannes Gutenberg University Mainz, 55099 Mainz, Germany, isabel.schnabel@uni-mainz.de.
} 


\section{Introduction}

In recent years, banks were harshly criticized for paying overly generous bonuses to bank managers. Much of the discussion focused on equity concerns. Many observers considered it unfair that banks paid out high bonuses after they had suffered unprecedented losses and had to be bailed out by the government. It seemed that bail-out money had been moved directly from the taxpayers' into the bank managers' pockets. Moreover, banks' profits had been boosted by favorable refinancing conditions due to public bail-out guarantees.

We present a simple model showing that steeper bonus schemes can be an optimal response of bank shareholders to increasing bail-out expectations, leading to higher risk-taking and a higher default probability of banks. This yields a rationale for imposing regulatory ceilings on bank bonuses, especially after a large-scale financial crisis. In contrast, raising managers' liability, as suggested in recent policy discussions, can be counterproductive because it raises risk-shifting incentives.

The underlying economic argument is intuitive. Shareholders design compensation schemes to influence bank managers' behavior. In a risk-shifting setup, bank shareholders with limited liability have an incentive to take excessive risk. Bonus schemes can be used to implement the desired risk level. Market discipline by (uninsured) lenders counteracts such incentives. However, bank bail-outs raise expected bail-out probabilities and thereby destroy market discipline. Therefore, shareholders react to an increase in bail-out expectations by designing steeper compensation (bonus) schemes to induce managers to take higher risk. In such a setup, ceilings on bonus payments are welfare-increasing, especially if bail-outs are expected with a high probability.

But there may also be a downside to bonus restrictions: they curb managers' efforts. If there is an effort problem between the shareholder and the manager, steep compensation schemes can be used to induce effort by the bank manager. The anticipation of a bail-out generates a larger positive externality of effort on the deposit insurance and the taxpayer, and thus induces shareholders to offer a flatter compensation scheme. This leads to an inefficiently low effort by the manager. In such a setup, ceilings on bonus payments are either harmful or at best ineffective. 
In reality, both types of agency problems are likely to be present. We discuss the conditions under which a ceiling on bank bonuses raises welfare in a setup with a risk-shifting and an effort problem. Our analysis shows that a sufficiently large increase in bail-out perceptions always makes it optimal for a welfare-maximizing regulator to impose ceilings on bank bonuses. This implies that bonus restrictions are desirable especially for banks with high bail-out probabilities, that is for systemically important financial institutions (SIFIs). Moreover, the benefits of bonus restrictions depend on the relative importance of risk-shifting versus effort problems. Bonus caps are most appropriate if risk-shifting problems are pervasive, for example, because regulatory frameworks are weak. Also, banks with a high share of non-traditional banking activities may be more prone to risk shifting, which, according to our model, calls for the introduction of stricter bonus regulations for such institutions.

We discuss alternative instruments to solve banks' incentive problems. In some circumstances, a risk-sensitive deposit insurance is able to restore market discipline, compensating for the negative incentive effects of rising bail-out expectations. However, this will not be possible if the bail-out probability is very high because deposit insurance premia will still be almost flat. Then bonus caps are more effective.

We also consider the effects of increasing bank manager's liability on banks' risk and effort choices. In the risk model, increased liability of the manager exacerbates the risk-shifting problem and lowers welfare. The manager can now be pushed to his participation constraint, and it becomes cheaper to incentivize him. Therefore, the shareholder induces him to take even more risk. In contrast, raising the manager's liability increases welfare in the effort model. It becomes cheaper to incentivize the manager to exert effort, and the bank becomes safer in equilibrium. The negative effect of increased liability can be avoided if the government sets the liability rules, rather than the shareholders. Taken together, these results strengthen the case for bonus restrictions if risk-shifting problems are dominant and if liability rules are determined by shareholders.

Finally, we briefly discuss the role of competition. Higher competition in the deposit (and lending) market is shown to raise the desirability of bonus caps because it increases the gains from risk-shifting. Competition for managers pushes "high-type" 
bank managers out of the banking sector in the presence of bonus ceilings, which may or may not be desirable.

Let us briefly discuss how our paper fits into the existing literature. While the literature on the corporate governance of non-financial firms is very broad, ${ }^{1}$ the literature on the corporate governance of banks is smaller, but developing quickly. Caprio and Levine (2002) stress two differences between banks and non-financial firms: the greater opaqueness of banks, which exacerbates agency problems, and the safety net, which affects the governance of banks in various ways, most importantly by increasing risk-shifting incentives.

The relationship between agency problems and management compensation in banking was hardly analyzed before the financial crisis, but is now on the top of the agenda of both academics and policy makers. Early work by John and John (1993) shows that a bank owner can commit to a certain level of risk-taking by setting management compensation schemes. This allows the shareholders to reestablish full market discipline, yielding the first-best level of risk (see also John, Saunders, and Senbet, 2000). The model implies that the risk sensitivity of bank manager compensation is lower when the risk-shifting problem is severe. In a similar vein, John, Mehran, and Qian (2010) argue that risk sensitivity should be low when monitoring by subordinated debt holders or the regulator is weak. Empirical results confirm that the performance-sensitivity of bank CEO contracts is low when a bank's leverage is high and outside monitoring is not very intense (John, Mehran, and Qian, 2010). In light of the recent crisis, the presumption that bank manager compensation reestablishes market discipline seems questionable. In our model, the main results are driven by the lack of market discipline. ${ }^{2}$

Several papers empirically analyze the relationship between management compensation and bank risk-taking. Early evidence by Houston and James (1995) suggests that compensation schemes in the banking sector did not promote risk-taking more

\footnotetext{
${ }^{1}$ See Shleifer and Vishny (1997), Prendergast (1999), and Becht, Bolton, and Röell (2003) for excellent surveys.

${ }^{2}$ Bannier, Feess, and Packham (2013) show that socially excessive risk-taking may arise even if banks themselves are not subject to a risk-shifting problem because bonus contracts may be used as screening devices to distinguish low and high ability workers.
} 
than in other sectors. More recent evidence points in the opposite direction. Cheng, Hong, and Scheinkman (2010) document a close connection between bank compensation and risk-taking. Bebchuk, Cohen, and Spamann (2010) find that compensation schemes at Bear Stearns and Lehman promoted excessive risk-taking in the run-up to the financial crisis. Chesney, Stromberg, and Wagner (2010) show that higher risk-taking incentives for managers translated into higher bank losses in the United States. Interestingly, banks with a better alignment of interests between managers and shareholders performed worse than others in the financial crisis (see Fahlenbrach and Stulz, 2011; Gropp and Köhler, 2010). In the same vein, Laeven and Levine (2009) find that banks with more powerful shareholders take higher risks. ${ }^{3}$ These findings are consistent with the idea that better aligned interests raised incentives to take risks, which then materialized in the crisis.

The earlier literature - and much of the policy discussion - focuses on the agency problem between shareholders and managers, rather than on that between shareholders and debt holders. Therefore, many policy suggestions aim at aligning the interests of shareholders and managers, which may come at the price of raising riskshifting incentives. Our paper considers both agency conflicts: bank shareholders use bonus payments as an instrument to incentivize managers to exert effort (thus mitigating the agency problem between managers and shareholders) and to take risk (thereby exacerbating the agency problem between shareholders and debt holders or the deposit insurance). We then show which agency problem dominates under which conditions.

The importance of the safety net for banks' risk-taking behavior is a recurrent theme in the literature on the role of market discipline in banking (see, e. g., Demirgüç-Kunt and Huizinga, 2004; Gropp, Hakenes, and Schnabel, 2011). However, the relationship between the safety net and bank manager compensation schemes has hardly been analyzed. The extension of the safety net, especially for SIFIs, is one of the most important consequences of the crisis. In order to design proper bank management compensation schemes after the crisis, we have to understand the implications of higher bail-out probabilites for the incentive effects of bank management compen-

\footnotetext{
${ }^{3}$ Moreover, they show that the effects of banking regulation depend on corporate governance structures.
} 
sation. In this regard, our work is also related to the paper by Freixas and Rochet (2013), which derives an optimal regulation of SIFIs including-besides systemic risk taxes and resolution procedures - supervisory control of bank compensation. This finding coincides nicely with the results from our model.

The paper proceeds as follows. In Section 2, we introduce the basic setup of our model. In Section 3, we derive the optimal manager compensation scheme and the effect of anticipated bank bail-outs in a setup where the manager can determine the bank's risk. In this setup, ceilings on bonuses are shown to be beneficial. In Section 4 , we analyze optimal compensation schemes if the manager faces an effort choice. Now ceilings on bonus payments are shown to be harmful because they exacerbate the underinvestment problem. Section 5 presents a general model including a risk and an effort choice. Ceilings on bonuses are shown to be desirable if bailout expectations are high enough. Section 6 discusses policy responses. First, we interpret the central policy parameters of the model. Then we discuss risk-sensitive deposit insurance and an increase in the manager's liability as alternative policy instruments. Finally, we analyze the role of competition in the banking sector. Section 7 concludes.

\section{Model Setup}

Consider a bank with a fixed asset volume of 1 , which is financed by insured deposits $d$, uninsured liabilities $l$, and equity $k \cdot{ }^{4}$ Uninsured liabilities are provided by lenders who demand an expected return of $r_{l}$. Deposits are provided by depositors who are covered by deposit insurance and demand an expected return of $r_{d}$. The deposit insurance demands a fixed premium of $\delta$ per unit of deposits, which is paid ex ante out of the deposit volume. ${ }^{5}$ The bank's balance sheet identity is thus $(1-\delta) d+l+k=1$. The bank's assets consist of a risky portfolio that yields a high return $Y_{h}$ with probability $p_{h}>0$, a medium return $Y_{m}<Y_{h}$ with probability

\footnotetext{
${ }^{4}$ All volumes $d, l$, and $k$ are treated as exogenous. This can be justified by segmented markets with different expected returns $r_{k}>r_{l}>r_{d}$. The bank then takes as much of the cheapest financing source as possible, hence volumes are given.

${ }^{5} \mathrm{~A}$ risk-sensitive deposit insurance premium is discussed in the policy section 6.2.
} 
$p_{m}>0$, and a low return $Y_{l}=0$ with probability $p_{l}=1-p_{h}-p_{m}>0 .{ }^{6}$ The return is observable. We assume that the medium payoff $Y_{m}$ is high enough to repay depositors and lenders, hence default may only occur if the low payoff $Y_{l}=0$ realizes. In this case, the government bails out the bank's depositors and lenders with (exogenous) probability $\beta$. Shareholders are not bailed out, such that their profits are zero when the low outcome realizes.

The bank is run by a penniless, risk-neutral manager with limited liability whose compensation scheme $\left(z_{h}, z_{m}, z_{l}\right)$ may depend on the realized payoff. ${ }^{7}$ The manager can influence the return structure of the bank portfolio by choosing an action that has an impact on the three probabilities, as will be described below. The bank is owned by a single shareholder who is the residual claimant and is subject to limited liability. The shareholder determines the compensation scheme of the manager. Due to deposit insurance, the deposit rate does not depend on the bank's risk-taking. In contrast, the interest rate demanded by lenders depends on anticipated risk.

We distinguish between three settings. In the first setting, discussed in Section 3, the manager chooses $a$, which is a measure of risk-taking. An increase in $a$ leads to a mean-preserving spread, raising risk, but leaving the mean return unchanged. Hence, an increase in $a$ results in a distribution that is second-order stochastically dominated. The manager incurs a private non-monetary cost of risk-taking, $c(a){ }^{8}$ In the second setting, discussed in Section 4, the expected return depends positively on the manager's effort $e$, which raises the bank's expected profits. An increase in $e$ entails first-order stochastic dominance. Again the manager incurs a non-monetary cost, $c(e)$. The third setting is a linear combination of the first and second one, including risk and effort choices. The timing of the model is given in Figure 1.

\footnotetext{
${ }^{6}$ This three-point distribution has been used, for example, by Biais and Casamatta (1999). It is the simplest class of distributions that contains mean-preserving spreads where the principal cannot infer the action from observing the payoff.

${ }^{7}$ Risk aversion would also be a natural assumption. In that case, a contingent bonus payment automatically implies higher risk for the manager, for which he will request a premium. In our modeling structure, but with a concave utility function, the manager would be less motivated by large payments, and it would therefore be more costly for the shareholder to incentivize the manager. Our results would change quantitatively, but not qualitatively.

${ }^{8}$ For simplicity, we assume quadratic cost functions. Any convex function would be sufficient, as long as it yields an inner optimum.
} 
Figure 1: Time structure

- $t=0$ : The shareholder offers a contract to the manager who can accept or reject.

- Lenders and depositors observe the contract and set interest rates.

The shareholder takes in deposits $d$, other liabilities $l$, inserts equity $k=$ $1-(1-\delta) d-l$, pays the deposit insurance premium $\delta d$, and invests 1 .

- The manager chooses a (or $e$ ), incurring non-monetary costs $c(a)$ (or $c(e)$ ).

- $t=1$ : The bank portfolio returns are realized. If the payoff is high or medium, all creditors are repaid; if the payoff is low, the bank is bailed out with probability $\beta$. Otherwise the deposit insurance repays the depositors.

\section{Risk Choice}

In the first setting, we assume that the manager's action $a$ affects the risk of the bank's portfolio, but not its mean return. We first describe the bank's return structure. Then we derive the bank's optimal compensation scheme, the manager's effort choice, and the effects of anticipated bank bail-outs.

Return structure of the bank's assets. In this version of the model, we assume that an increase in $a$ shifts probability mass from the medium outcome to the two extreme outcomes. We parameterize this in the following way: ${ }^{9}$

$$
\begin{aligned}
p_{h}(a) & =p_{h}^{0}+\frac{a}{Y_{h}\left(Y_{h}-Y_{m}\right)} \\
p_{m}(a) & =p_{m}^{0}-\frac{a}{Y_{m}\left(Y_{h}-Y_{m}\right)} \\
p_{l}(a) & =1-p_{h}(a)-p_{m}(a)=\left(1-p_{h}^{0}-p_{m}^{0}\right)+\frac{a}{Y_{h} Y_{m}}
\end{aligned}
$$

An example of such a distribution function is plotted in Figure 2 for two different values of action $a$. An increase in $a$ raises the probability of the highest and the lowest return, but lowers the probability of the medium return, resulting in a mean-

\footnotetext{
${ }^{9}$ To ensure non-negative probabilities, $a$ must lie between 0 and the minimum of $\left(1-p_{h}^{0}\right) Y_{h}\left(Y_{h}-\right.$ $\left.Y_{m}\right), p_{m}^{0} Y_{h}\left(Y_{h}-Y_{m}\right)$, and $\left(1-p_{l}^{0}\right) Y_{h} Y_{m}$.
} 
Figure 2: Return distribution depending on risk choice
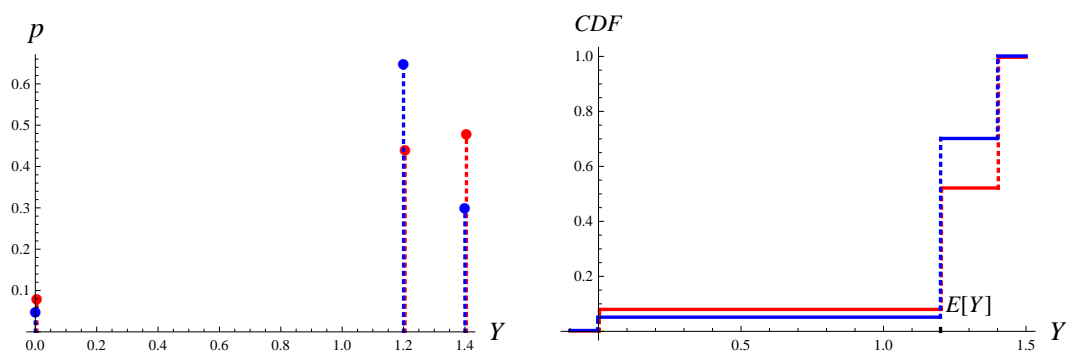

These pictures show a possible distribution of returns with $Y_{h}=1.4, Y_{m}=1.2, Y_{l}=0$, and $p_{h}^{0}=0.30, p_{m}^{0}=0.65, p_{l}^{0}=0.05$, for $a=0$ (blue) and $a=0.05$ (red). The probability density function is on the left, the cumulative distribution function on the right.

preserving spread. The expected return $E[Y]$ does not depend on $a$, whereas the variance increases in $a$ (in fact, it increases one-to-one in $a$ ).

Action a measures active risk-taking by the bank manager, resulting in a private non-monetary cost, $c(a)=\alpha a^{2} / 2$. If the manager is inactive $(a=0)$, the bank portfolio has some "natural" risk level. The manager can exert a costly effort to deviate from this natural risk level. For example, he could reduce risk by an action $a<0$, or increase risk by an action $a>0$, both coming at a positive cost. Only $a>0$ will occur in equilibrium, therefore we concentrate on the according interpretation. The cost $c(a)$ can be interpreted as the cost of moving the bank's portfolio away from the natural portfolio structure. The manager must look for borrowers with certain risk characteristics, buy and sell assets, or move into new asset classes. The implicit assumption is that changes in the portfolio initially hardly entail any cost, $c^{\prime}(0)=0$. The farther the portfolio is from its natural level, the more difficult (and costly) it becomes to change bank risk, $c^{\prime \prime}(a)>0 . c(a)$ can also be interpreted as the cost of hiding risk-taking from supervisors. A quadratic specification of the cost function seems appropriate as re-organizing the portfolio can induce price movements if markets are not perfectly liquid, implying non-linear costs. Also, hiding risk is more difficult for higher deviations from the natural level.

The first-best choice of a maximizes $E[Y]-c(a)$. Given that the mean $E[Y]$ does not depend on $a$ and that $c(a)$ strictly increases in $a$, the first-best choice is $a=0$. Hence, any active risk-taking is inefficient. We now analyze the manager's risk choice (depending on the compensation scheme set by the shareholder). 
Bonus contract. Project returns are verifiable, hence the shareholder offers the manager a compensation scheme $\left(z_{h}, z_{m}, z_{l}\right)$ that depends on the realized outcome. Because the bank manager is subject to limited liability, all entries of the compensation scheme must be non-negative, $z_{h} \geq 0, z_{m} \geq 0$, and $z_{l} \geq 0$.

If the outcome is low, $Y_{l}=0$, the payment can be neither positive (there are no returns to be distributed), nor negative (because the manager is subject to limited liability), thus $z_{l}=0$. The equity holder is the residual claimant. Due to the convex return structure, he wants the manager to take risk. Because more risk moves probability mass away from the medium outcome, the shareholder never rewards the manager in the medium outcome as this would set incentives for lower risk-taking. Therefore, $z_{m}=0$. Finally, the shareholder can reward the high outcome with a bonus payment in order to set incentives for higher risk-taking. This is profitable if the costs of risk-taking are not too large relative to the gain from risk-shifting. Consequently, the manager receives positive payments only when the high outcome is realized, $z_{h} \geq 0$. This leaves us with $z_{h}$ as the only endogenous variable. Hence, the compensation scheme looks like a bonus contract. The manager receives a bonus if the project is very successful; under the two other outcomes, he does not receive any payment.

Manager's optimization problem. We solve the model by backward induction, first looking at the bank manager's optimization problem. His expected profits are

$$
\Pi_{M}=p_{h}(a) z_{h}-\frac{\alpha}{2} a^{2}=\left(p_{h}^{0}+\frac{a}{Y_{h}\left(Y_{h}-Y_{m}\right)}\right) z_{h}-\alpha a^{2} / 2
$$

which is maximized for

$$
a^{*}\left(z_{h}\right)=\frac{z_{h}}{Y_{h}\left(Y_{h}-Y_{m}\right) \alpha} .
$$

We see immediately that a higher bonus (higher $z_{h}$ ) induces higher risk-taking $a$. Risk-taking depends negatively on the cost parameter $\alpha$.

Participation constraints in the presence of bail-outs. We now consider the participation constraints of lenders and depositors. In expectation, the risk-neutral lenders need to recover their opportunity costs in order to be willing to participate. Let $L$ denote the promised repayment to lenders (including principal and interest 
payments). The debt can always be repaid in the high and medium outcomes. When the low outcome realizes, the bank cannot repay anything. However, lenders are bailed out by the government with probability $\beta$. We assume for simplicity that the government repays only the nominal loan value, but not interest rates. ${ }^{10}$ The lenders' breakeven condition is then

$$
\begin{aligned}
{\left[p_{h}(a)+p_{m}(a)\right] L+p_{l}(a) \beta l } & =\left(1+r_{l}\right) l \\
\Longrightarrow L & =l \cdot \frac{\left(1+r_{l}\right)-p_{l}(a) \beta}{p_{h}(a)+p_{m}(a)}
\end{aligned}
$$

The promised repayment depends positively on the default probability $p_{l}(a)=1-$ $p_{h}(a)-p_{m}(a)$, and negatively on the bail-out probability $\beta$. In contrast to uninsured lenders, depositors are always repaid, either by the bank, the government, or the deposit insurance. Therefore, their breakeven condition is simply

$$
D=\left(1+r_{d}\right) d
$$

where $D$ is the promised repayment to depositors.

Shareholder's optimization problem. The expected profits of the shareholder $(E)$ are given by

$$
\Pi_{E}=p_{h}(a)\left(Y_{h}-D-L-z_{h}\right)+p_{m}(a)\left(Y_{m}-D-L\right)-\delta .
$$

The shareholder chooses $z_{h}$ to maximize expected profits. Importantly, the choice of $z_{h}$ is observable by lenders and depositors who can therefore fully anticipate the agent's risk choice $a^{*}\left(z_{h}\right)$. Hence, substituting $L$ and $D$ into expected profits, substituting $a^{*}\left(z_{h}\right)$, taking the first-order condition and solving for $z_{h}$ yields

$$
z_{h}^{*}=\frac{Y_{h}-Y_{m}}{2 Y_{m}}\left(\left[\beta l+\left(1+r_{d}\right) d\right]-\alpha p_{h}^{0} Y_{h}^{2} Y_{m}\left(Y_{h}-Y_{m}\right)\right) .
$$

\footnotetext{
${ }^{10}$ This assumption facilitates calculations substantially. If interest payments were also covered by the bail-out, the value of the bail-out would depend on the level of interest rates (which, in turn, are a function of bail-outs). The resulting feedback effects make the model algebraically intractable. Numerical examples show that the differences are negligible, as long as the bank's default probability is not too large. Note that the same problem does not occur with insured deposits, as the deposit insurance premium is paid ex ante and thus does not cause comparable feedback effects.
} 
The optimal bonus payment depends positively on the term in brackets, which is the debt repayment that can be shifted to third parties (the government or deposit insurance) in case of default, which determines the gains from risk-shifting. Through this channel, the bonus $z_{h}^{*}$ increases in $\beta$. Hence, the expectation of bail-outs makes the bonus scheme steeper. The cost of risk-taking, $\alpha$, lowers the optimal bonus. Some algebra shows that $z_{h}^{*}<Y_{h}$, hence the bonus can always be paid and never exceeds the bank's capacities.

Equation (7) describes the optimal $z_{h}$ only if this expression is positive. If it is negative, the shareholder will choose $z_{h}^{*}=0$. Then, the manager's contract is flat, $z_{h}^{*}=z_{m}^{*}=z_{l}^{*}=0$, and he accordingly chooses not to increase risk, $a^{*}=0$. Intuitively, this will be the case if inducing the manager to shift risk is expensive (high $\alpha$ ) or if the debt repayment that can be shifted to the government is small (low $\beta$ ). Formally, $z_{h}^{*}>0$ if

$$
\beta l>\alpha p_{h}^{0} Y_{h}^{2}\left(Y_{h}-Y_{m}\right) Y_{m}-\left(1+r_{d}\right) d
$$

In the following, we will focus on interior solutions, where condition (8) holds. Plugging (7) into (3), we obtain the equilibrium value of $a^{*}$,

$$
a^{*}=\frac{\beta l+\left(1+r_{d}\right) d}{2 Y_{h} Y_{m} \alpha}-\frac{p_{h}^{0} Y_{h}\left(Y_{h}-Y_{m}\right)}{2} .
$$

Effect of bail-out expectations. In the interior solution, the shareholder wants the manager to take excessive risk, $a^{*}>0$. Since the shareholder himself is subject to limited liability, he can shift losses to the deposit insurance and the government. We see that equilibrium risk-shifting increases in the bail-out probability $\beta$ (and hence the gain from risk-taking), implying an increase in the default probability $p_{l}(a)$ of the bank. The manager benefits from the expected bail-out, $\mathrm{d} \Pi_{M} / \mathrm{d} \beta>0$, because he must be given a rent to induce him to take risk. The expected compensation of the manager $p_{h}\left(a^{*}\right) z_{h}^{*}$ also increases. These results are summarized in the following proposition, and are proven formally in the Appendix.

Proposition 1 (Bail-outs in the risk model) Assume that the bank manager is subject to a risk-shifting problem. In an interior solution, an increase in the bail-out probability of the bank 
1. makes the bonus scheme steeper $\left(d z_{h}^{*} / d \beta>0\right)$,

2. raises the manager's risk-taking $a^{*}$, implying that the bank's probability of default $p_{l}\left(a^{*}\right)$ also increases,

3. raises the expected compensation $p_{h}\left(a^{*}\right) z_{h}^{*}$ and the expected profit of the manager.

The intuition is simple: In the presence of bail-outs, market discipline is weakened and bank lenders no longer "punish" their bank for higher (anticipated) risk-taking by demanding higher interest rates. This implies that the risk-shifting problem is exacerbated because the bank can now shift even more losses to other parties (the deposit insurance and the government). The shareholder hence wants to give the bank manager an incentive to take higher risks. This is done through a steeper bonus contract. Because of his limited liability, not only the shareholder, but also the manager benefits from the bail-out guarantee. ${ }^{11}$

From a welfare perspective, risk-shifting $(a>0)$ is always suboptimal in this model. Since the mean of the return distribution is unchanged by risk-shifting, the welfare loss stems only from the costs $c(a)$. Welfare can be improved by regulating the manager's compensation scheme. Specifically, a cap on bonus payments would lead to lower risk-shifting and, hence, to an increase in welfare. Since bonus payments are never beneficial from a welfare perspective in this setup, a complete ban of bonus payments yields the first-best.

Corollary 1 (Caps on bonus payments) Assume that the bank manager is subject to a risk-shifting problem. In an interior solution, a binding regulatory cap on bonus payments reduces risk-shifting and the bank's probability of default, and increases welfare. The positive welfare effect of a given cap increases in the bail-out probability $\beta$. A ban of bonus payments eliminates risk-shifting completely.

\footnotetext{
${ }^{11}$ This aspect will be crucial in the discussion of increased liability of the manager.
} 


\section{Effort Choice}

We now consider an alternative setting, in which the manager can exert effort in order to increase the mean return of the bank's portfolio. In Section 5, we then combine the two models and consider the general case in which the manager can choose risk and effort. We start by describing the bank's return structure before analyzing compensation schemes, effort choices, and the effects of anticipated bank bail-outs.

Return structure of the bank's assets. Assume that managers can exert effort in order to increase the mean return of the bank by moving probability mass from worse outcomes to better ones. For concreteness, we assume the following return structure,

$$
\begin{aligned}
p_{h}(e) & =p_{h}^{0}+e \\
p_{m}(e) & =p_{m}^{0} \\
p_{l}(e) & =1-p_{h}(e)-p_{m}(e)=\left(1-p_{h}^{0}-p_{m}^{0}\right)-e,
\end{aligned}
$$

with $e$ in the range where none of the probabilities turns negative. With this parametrization, an increase in effort $e$ shifts probability mass from the worst to the best outcome, hence it leads to a new distribution that first-degree stochastically dominates the original distribution (see Figure 3). The assumed shift of probability mass is equivalent to one where an equal probability mass is shifted from the low to the medium, and from the medium to the high outcome. More general shifts of the probability mass are discussed below.

In exerting effort, the manager incurs a private non-monetary cost, $c(e)=\eta e^{2} / 2$. This cost can, for example, be interpreted as the cost of monitoring the bank portfolio. Under the given cost function, the first-best level of effort is $e=Y_{h} / \eta$.

Bonus contract. As before, compensation cannot be negative (due to limited liability) and cannot exceed portfolio returns. In order to induce effort, the shareholder rewards the high outcome with a bonus. Using similar arguments as above, 
Figure 3: Return distribution depending on effort choice
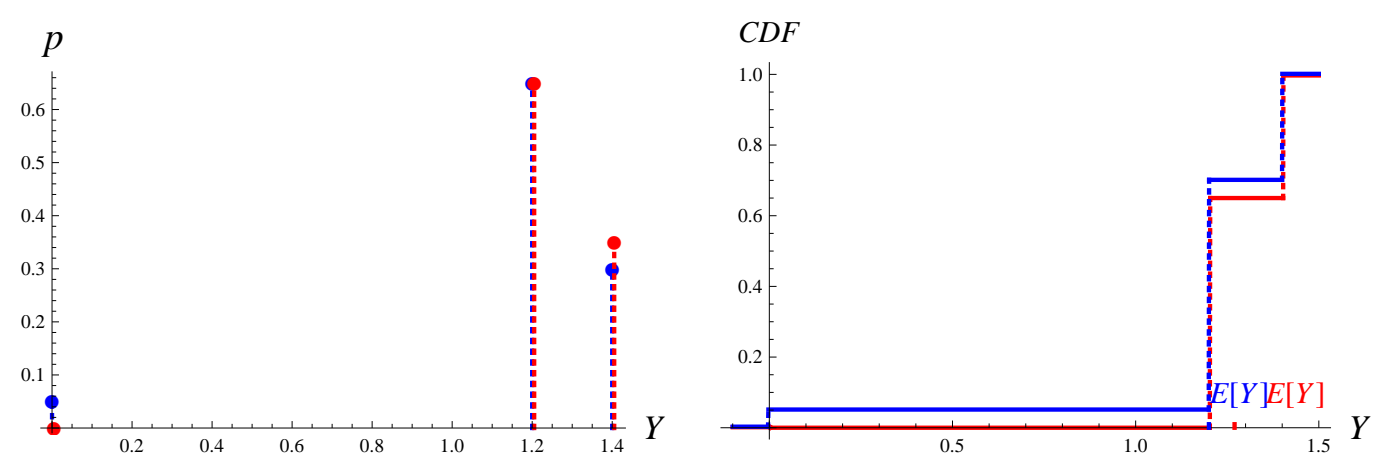

This picture shows a possible distribution of returns with $Y_{h}=1.4, Y_{m}=1.2, Y_{l}=0$, and $p_{h}^{0}=0.30, p_{m}^{0}=0.65, p_{l}^{0}=0.05$, for $e=0$ (blue) and $e=0.05$ (red). The probability density function is on the left, the cumulative distribution function on the right.

$z_{l}=z_{m}=0$ in equilibrium, so $z_{h}$ is the only endogenous variable. The first-order condition of the manager's optimization problem yields

$$
e^{*}=\frac{z_{h}}{\eta}
$$

Hence, a higher bonus induces a higher effort level; higher costs reduce effort.

The participation constraints of lenders and depositors are identical to those in Section 3, such that equations (4) and (5) apply. Plugging these in the shareholder's profit function and considering the first-order condition for the optimal contract yields

$$
\begin{aligned}
z_{h}^{*} & =\frac{1}{2}\left(Y_{h}-\beta l-\left(1+r_{d}\right) d-\eta p_{h}^{0}\right), \\
e^{*} & =\frac{1}{2 \eta}\left(Y_{h}-\beta l-\left(1+r_{d}\right) d-\eta p_{h}^{0}\right) .
\end{aligned}
$$

For $\beta l>Y_{h}-\left(1+r_{d}\right) d-\eta p_{h}^{0}$, the optimal contract becomes flat, $z_{h}^{*}=0$. Hence, effort also becomes zero, $e^{*}=0$. This occurs if inducing the manager to exert effort is expensive (high $\eta$ ), or if the risk-insensitive part of debt, $\beta l+\left(1+r_{d}\right) d$, is large. The latter result arises from the fact that, if debt is largely risk-insensitive, funding costs hardly react to higher effort, making it less attractive to pay bonuses.

We see that equilibrium effort is below the first-best level. The reason is that higher effort partly benefits the manager (who obtains a rent), the deposit insurance, and the government who all benefit from a lower default probability. Therefore, 
the shareholder has insufficient incentives to implement a contract that entails the efficient effort level. There is an underinvestment problem.

Effect of bail-out expectations. Taking the derivative of $z_{h}^{*}$ with respect to $\beta$, we find that the anticipation of bail-outs leads to a flatter compensation scheme, and hence to an even lower effort choice, implying an increase in the bank's default probability $p_{l}\left(e^{*}\right)$. The reason is the increase in the positive externality of effort on the deposit insurance or the government, which is not taken into account by the shareholder when designing the compensation package. Hence, bail-outs are again harmful (just as in the risk-shifting setup), but for a different reason. In this setup, they exacerbate the underinvestment problem.

Proposition 2 (Bail-outs in the effort model) Assume that the bank manager is subject to an effort problem. In an interior solution, an increase in the bail-out probability of the bank

1. makes the bonus scheme flatter ( $z_{h}^{*}$ decreases),

2. lowers the manager's effort $e^{*}$, implying that the bank's probability of default $p_{l}\left(e^{*}\right)$ increases,

3. lowers the expected compensation $p_{h}\left(e^{*}\right) z_{h}^{*}$ and the expected profit of the manager.

Now the judgment of caps on bonus payments is very different from Section 3. From a welfare perspective, the manager's effort choice is always suboptimally low. A binding cap on bonus payments would worsen the manager's choice and exacerbate the underinvestment problem. When bail-out expectations go up, the bonus scheme becomes even flatter. This implies that caps on bonuses would potentially become ineffective because they would no longer be binding. Hence, a cap on bonuses would be harmful or, at best, ineffective in this setting.

Corollary 2 (Caps on bonus payments) Assume that the manager is subject to an effort problem. In an interior solution, a binding regulatory cap on bonus payments lowers effort, raises the bank's probability of default, and reduces welfare. Moreover, the anticipation of bail-outs makes bonus caps less effective. 
Let us briefly discuss what would happen if effort shifted probability mass from the low to the medium outcome. The shareholder would then like to reward the manager for the medium outcome. But then, the manager's contract would have $z_{l}=0, z_{m}>0$, and $z_{h}=0$. The probability of the high outcome cannot be changed, thus the shareholder does not want to reward it. Apart from that, the basic economic problem is the same, and comparative statics are unchanged. ${ }^{12}$ If effort shifts probability mass from the medium to the high outcome, there is no interaction with the bail-out probability. Summing up, a focus on the probability shift described by equation (10) does not seem to restrict generality unduly.

\section{General Model with Risk and Effort Choices}

We now consider a generalization of Sections 3 and 4, in which the manager can influence the return distribution by choosing risk and effort.

Return structure of the bank's assets. We now assume that the manager can take risk by choosing $a$ at a private cost $\alpha a^{2} / 2$, and increase the mean return by exerting an effort $e$ at a private cost $\eta e^{2} / 2$. The return distribution is given by

$$
\begin{aligned}
& p_{h}(e, a)=p_{h}^{0}+e+\frac{a}{Y_{h}\left(Y_{h}-Y_{m}\right)} \\
& p_{m}(e, a)=p_{m}^{0}-\frac{a}{Y_{m}\left(Y_{h}-Y_{m}\right)} \\
& p_{l}(e, a)=1-p_{h}(e, a)-p_{m}(e, a)=\left(1-p_{h}^{0}-p_{m}^{0}\right)-e+\frac{a}{Y_{h} Y_{m}} .
\end{aligned}
$$

The two earlier models are limiting cases of the general model for $\eta \rightarrow \infty$ and $\alpha \rightarrow \infty$, respectively. If effort costs are extremely high, the effort choice is irrelevant and we are back in the risk choice framework from Section 3. If instead risk-taking costs become prohibitive, we are left with the model of effort choice from Section 4. Note that effort and risk do not interact in the return distribution. But even with this simple specification, the two choices interact in an interesting way. Due to the separability of the distribution functions regarding $a$ and $e$, the first-best choices are unchanged: $a=0$ and $e=Y_{h} / \eta$.

\footnotetext{
${ }^{12}$ This is due to the fact that a third outcome is not necessary for the effort model. It is used only to generate consistency between Sections 3,4 , and 5 .
} 
Bonus contract. Unsurprisingly, the compensation scheme has the same structure as before. Only $z_{h}$ is positive in equilibrium, and $z_{m}=z_{l}=0$. This implies that the shareholder has only one instrument to influence the two choice parameters of the manager. Following an analogous procedure as above, we obtain the same expressions as above,

$$
\begin{aligned}
a^{*} & =\frac{z_{h}}{Y_{h}\left(Y_{h}-Y_{m}\right) \alpha}, \\
e^{*} & =\frac{z_{h}}{\eta} .
\end{aligned}
$$

Risk and effort are proportional to the bonus $z_{h}$. When $z_{h}$ goes up, the manager takes more risk $a$ and increases effort $e$.

Effect of bail-out expectations. The participation constraints for lenders and depositors are unchanged. Substituting these into the shareholder's profit function and deriving the first-order condition yields the optimal bonus,

$$
\begin{gathered}
z_{h}^{*}=\frac{Y_{h}-Y_{m}}{2 Y_{m}\left(\eta+\alpha Y_{h}^{2}\left(Y_{h}-Y_{m}\right)^{2}\right)} \cdot\left(\alpha Y_{h}^{2}\left(Y_{h}-Y_{m}\right) Y_{m}\left(Y_{h}-\beta l-\left(1+r_{d}\right) d\right)\right. \\
\left.\left.-\eta\left(\alpha p_{h}^{0} Y_{h}^{2}\left(Y_{h}-Y_{m}\right) Y_{m}-\beta l-\left(1+r_{d}\right) d\right)\right)\right) .
\end{gathered}
$$

This solution looks messy, but most terms stem from the normalization of the meanpreserving spread. In equilibrium, there is excessive risk-taking and an underinvestment in effort. But now the effect of anticipated bail-outs is ambiguous. Taking the derivative with respect to $\beta$ yields

$$
\frac{\mathrm{d} z_{h}^{*}}{\mathrm{~d} \beta}=\frac{Y_{h}-Y_{m}}{2 Y_{m}} \cdot \frac{\eta / \alpha-Y_{h}^{2}\left(Y_{h}-Y_{m}\right) Y_{m}}{\eta / \alpha+Y_{h}^{2}\left(Y_{h}-Y_{m}\right)^{2}} \cdot l
$$

This derivative is positive if and only if

$$
\frac{\eta}{\alpha}>Y_{h}^{2} Y_{m}\left(Y_{h}-Y_{m}\right)
$$

Hence, the effect of an anticipated bail-out now depends on the relative importance of the risk-shifting and the effort problem. This result is intuitive. If $\beta$ increases, the shareholder adjusts the contract for the manager. There are two countervailing effects. First, as in Section 3, an increase in risk becomes more attractive for the shareholder, so he wants to increase $z_{h}$. This channel is particularly strong if risktaking is relatively cheap, hence if $\eta / \alpha$ is large. Then the manager strongly adjusts 
risk-taking in reaction to a higher bonus payment, while effort is hardly adjusted. Second, as in Section 4, a high effort $e$ becomes less attractive for the shareholder, so he wants to reduce $z_{h}$. This channel is particularly strong if $\eta / \alpha$ is small. Which of the two effect dominates depends on the relative size of $\eta$ and $\alpha$.

Proposition 3 (Bail-outs in the general model) Assume that the bank manager is subject to a risk-shifting and an effort problem. In an interior solution, an increase in the bail-out probability of the bank

1. makes the bonus scheme steeper ( $z_{h}^{*}$ increases) if and only if

$$
\frac{\eta}{\alpha}>Y_{h}^{2} Y_{m}\left(Y_{h}-Y_{m}\right)
$$

2. raises the manager's effort $e^{*}$ and risk choice $a^{*}$ under the same condition, but always raises the bank's probability of default $p_{l}\left(e^{*}, a^{*}\right)$,

3. raises the expected compensation $p_{h}\left(e^{*}, a^{*}\right) z_{h}^{*}$ and the expected profit of the manager under the same condition.

The welfare effects of caps on bonus payments are also ambiguous. In Section 3, we saw that a cap on bonuses may prohibit inefficient risk choices and therefore increase welfare. In Section 4, a cap curbs the manager's effort and is therefore undesirable. In the combined model, both effects are present, so the welfare effect of a cap is ambiguous.

To check under which conditions a cap on bonus payments is optimal from a welfare perspective, we derive the bonus that maximizes welfare. Welfare is defined as the aggregate net present value, net of the manager's non-monetary costs,

$$
W=p_{h} Y_{h}+p_{m} Y_{m}-\left(1+r_{d}\right) d-\left(1+r_{l}\right) l-\eta e^{2} / 2-\alpha a^{2} / 2
$$

$p_{h}, p_{m}, e$, and $a$ depend on $z_{h}$. The welfare-maximizing bonus is given by

$$
z_{h}^{W}=\frac{Y_{h}}{\frac{1}{Y_{h}^{2}\left(Y_{h}-Y_{m}\right)^{2}} \frac{\eta}{\alpha}+1} .
$$


The optimal bonus $z_{h}^{W}$ decreases in $\eta / \alpha$. If the risk-shifting problem is relatively important compared to the effort problem $(\eta / \alpha$ is relatively high), the welfareoptimal bonus is lower. ${ }^{13}$ If the equilibrium bonus $z_{h}^{*}$ from equation (16) exceeds the welfare-optimal bonus $z_{h}^{W}$, a cap on bonus payments raises welfare. If $z_{h}^{*}$ is smaller than $z_{h}^{W}$, the bonus payment implemented by the shareholder is too small from a welfare perspective because it induces too little effort. Hence, putting a cap on bonus payments is undesirable. A comparison of (16) and (20) shows that $z_{h}^{*}>z_{h}^{W}$ if and only if

$$
\beta l>\frac{\alpha Y_{h}^{2}\left(Y_{h}-Y_{m}\right) Y_{m}\left(Y_{h}+\eta p_{h}^{0}\right)}{\eta-\alpha Y_{h}^{2}\left(Y_{h}-Y_{m}\right) Y_{m}}-\left(1+r_{d}\right) d .
$$

This condition is illustrated in Figure 4 for different combinations of $\eta$ and $\alpha$. If $\alpha$ is small, risk-shifting is cheap. As a consequence, for a positive compensation $z_{h}^{*}$, the manager has strong risk-shifting incentives, leading to a reduction in welfare. Hence, for small $\alpha$, it is always optimal to reduce risk-shifting incentives by capping the bonus. This is also visible in the figure: for $\alpha \rightarrow 0$, capping bonuses is optimal for any positive $\beta$, independently of $\eta$. The argument for $\eta$ is the other way around. If $\eta$ is small, exerting effort is cheap, and with a positive $z_{h}^{*}$, the manager exerts a lot of effort. Then a cap on bonuses is never optimal because bank bonuses are already chosen too low by the shareholder. Finally, a cap is efficient if the bail-out probability $\beta$ is high. The larger $\beta$, the larger the risk-shifting motive of shareholders. The optimal bonus induces the manager to take excessive risk. As a result, the regulator should cap bonuses especially for high $\beta$, as is summarized in the following proposition.

Proposition 4 (Optimal caps on bonus payments) Assume that the bank manager is subject to a risk-shifting and an effort problem. In an interior solution, a higher bail-out probability raises the parameter space for which regulatory caps on bonus payments are optimal from a welfare perspective.

\footnotetext{
${ }^{13}$ These results are similar in spirit to John and John (1993) and John, Mehran, and Qian (2010). In their models, however, the welfare-optimal solution is equivalent to the optimal choice by the shareholder.
} 
Figure 4: Condition for a welfare-increasing effect of bonus caps

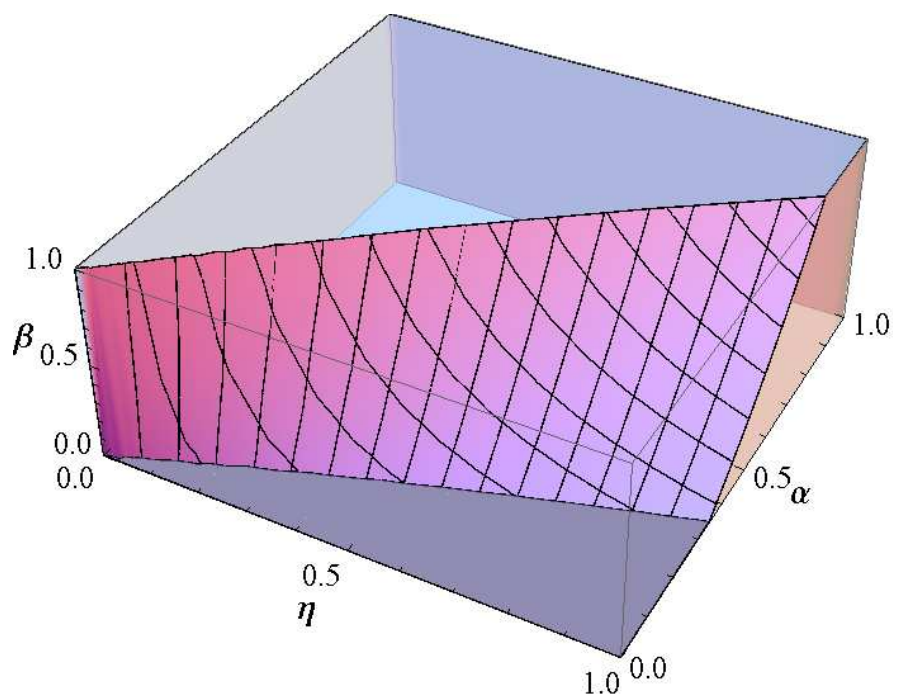

This simulation is again based on the parameters $Y_{h}=1.4$ and $Y_{m}=1.2$. For parameter combinations of $\beta, \eta$ and $\alpha$ above the plane, a cap on bonus payments raises welfare. If $\eta$ is close to zero, exerting effort is cheap, and it is never optimal to have restrictions on bonuses. If $\alpha$ is close to zero, risk-shifting is cheap, and it is always optimal to limit bonuses. The dependence on $\beta$ also depends on $\alpha$ and $\eta$. For low $\alpha$ or high $\eta$, a cap is always optimal. For high $\alpha$ or low $\eta$, a cap is never optimal. In between, a cap is optimal only if $\beta$ is high.

\section{$6 \quad$ Policy Implications}

This section discusses the policy implications of our model. We start by giving an interpretation of the central policy parameters of our model. Then we analyze the implications of risk-sensitive deposit insurance and discuss the desirability of raising manager liability, which is frequently suggested to improve bank manager behavior. Finally, we briefly consider the role of competition in the banking sector.

\subsection{Interpretation of Policy Parameters}

As shown by Figure 4, the welfare-maximizing policy regarding bank bonuses depends on three parameters: the bail-out probability $\beta$, the risk cost parameter $\alpha$, and the effort cost parameter $\eta$. 
The bail-out probability clearly is a central policy instrument. It depends, among other things, on past bail-out experiences and on existing resolution procedures aiming at reducing implicit bail-out guarantees. According to our model, bonus restrictions are more desirable in the presence of strong bail-out expectations. Hence, bonus restrictions are less needed in countries with credible resolution regimes. In contrast, bonus restrictions are crucial when past bail-outs raise bail-out expectations for the future. Hence, the recent calls for caps on bank bonuses in reaction to the recent financial crisis may well be justified. Given the huge bail-out packages to many banks, expected bail-out probabilities increased sharply. Our model also suggests that bonus restrictions are not equally important for all kinds of banks. According to the model, especially systemically important financial institutions (SIFIs) should be subjected to bonus restrictions. After the recent promises of government officials from many countries not to let any systemically relevant institution fail, bail-out probabilities of SIFIs rose substantially. It remains to be seen whether regulation will be able to curb such expectations.

The two cost parameters are best interpreted relatively to each other, as the policy implications depend on $\eta / \alpha$. This ratio can be interpreted as the relative cost of raising mean returns versus raising risk, or, equivalently, the relative importance of risk-shifting versus effort problems. Bonus restrictions are optimal when $\eta / \alpha$ is high. Hence, a first implication of our model is that bonus restrictions should be imposed if risk-shifting problems are relatively important compared to effort problems. Since risk-shifting is more prevalent in the financial than in the non-financial sector where effort problems dominate, bonus restrictions are more appropriate in the financial sector. The usefulness of bonus regulation will also depend on the institutional framework. Most importantly, an efficient regulatory system tends to make riskshifting more expensive, lowering $\eta / \alpha$ and making bonus restrictions less desirable. Finally, even within a given financial system, financial institutions differ regarding the cost ratio. In particular, raising risk will be less costly for non-traditional banking activities, such as trading or securitization, than for traditional banking, namely lending and deposit-taking. Technological innovations, which affect non-traditional banking activities more than traditional ones, reinforce this cost difference. This suggests that banks with a high share of non-traditional banking activities should rather be subjected to bonus restrictions than traditional deposit banks. 
Summing up, our model suggests that bonus restrictions are most appropriate in financial systems with weak regulatory frameworks without credible resolution procedures, and, within a given financial system, for systemically important financial institutions, especially those with a high share of non-traditional banking activities. In the following, we discuss alternative policy instruments that have been suggested to solve incentive problems in banking, namely risk-sensitive deposit insurance (Section 6.2) and enhanced liability of managers (Section 6.3), and compare them with bonus restrictions.

\subsection{Risk-Sensitive Deposit Insurance}

In our main model, we made the assumption that the deposit insurance premium is fixed, i. e., it does not adjust to the bank's risk. Here, we want to analyze the effects of risk-sensitive deposit insurance. We place the discussion in the context of the general model (with risk and effort choices).

The deposit insurance covers the promised repayment $D=\left(1+r_{d}\right) d$ with probability $p_{l}(1-\beta)$. Let $s$ measure the degree of sensitivity of the deposit insurance premium $\delta$

$$
\delta=s p_{l}(1-\beta)\left(1+r_{d}\right) d+(1-s) \delta_{0},
$$

where $\delta_{0}$ is the fixed premium for a completely insensitive premium. For $s=0$, the premium is flat as before, $\delta=\delta_{0}$. For $s=1$, the premium is fully risk sensitive, and the deposit insurance just breaks even. We assume that the deposit insurance has the same information as lenders. That is, it observes the manager's bonus contract, anticipates the manager's risk and effort choices and thus the probability of the low outcome $p_{l}$, and then sets $\delta$ accordingly.

Now the shareholder's problem of implementing the optimal contract changes. If the shareholder induces the manager to increase the probability of default, the premium $\delta$ will rise. Taking this into account, the new optimal contract becomes

$$
z_{h}^{*}=\left.z_{h}^{*}\right|_{s=0}-(1-\beta)\left(1+r_{d}\right) d \frac{Y_{h}-Y_{m}}{2 Y_{m}} \cdot \frac{\eta / \alpha-Y_{h}^{2}\left(Y_{h}-Y_{m}\right) Y_{m}}{\eta / \alpha+Y_{h}^{2}\left(Y_{h}-Y_{m}\right)^{2}} \cdot s .
$$

The payment $z_{h}^{*}$ can be decreasing or increasing in $s$, depending on whether the condition for higher bonuses in response to higher bail-out expectations, (18), holds 
or not. This result is intuitive. Both an increase in the bail-out probability (higher $\beta$ ) and a decrease in the risk-sensitivity of deposit insurance (lower $s$ ) insulate the shareholder from the consequences of the low outcome. Therefore, their effects go into the same direction. The corresponding probability of the low outcome is

$$
p_{l}=\left.p_{l}\right|_{s=0}-(1-\beta)\left(1+r_{d}\right) d \frac{\left(\eta / \alpha-Y_{h}^{2}\left(Y_{h}-Y_{m}\right) Y_{m}\right)^{2}}{2 \eta Y_{h}^{2} Y_{m}^{2}\left(\eta / \alpha+Y_{h}^{2}\left(Y_{h}-Y_{m}\right)^{2}\right)} \cdot s .
$$

Hence, a higher risk sensitivity $s$ of deposit insurance always reduces the probability $p_{l}$ (just as a lower bail-out probability always lowers the probability of the low outcome). Therefore, a higher risk sensitivity of deposit insurance can compensate for the negative effects of rising bail-out expectations.

However, the effectiveness of risk-sensitive deposit insurance depends on the level of the bail-out probability. If the bank is always bailed out, $\beta=1$, the deposit insurance never has to step in. In that situation, even a risk-sensitive deposit insurance would have a flat premium because it bears no risk. This also shows up in (23) and (24): the optimal payment $z_{h}^{*}$ and the probability $p_{l}$ do not depend on $s$ if $\beta=1$. Hence, a higher risk sensitivity of deposit insurance cannot always compensate for the negative effects of bail-out expectations. In contrast, bonus caps are effective even with very high bail-out expectations. Hence, we conclude that caps on bonuses are warranted especially if it is impossible to restore market discipline through other channels.

\subsection{Increased Liability of the Manager}

We now discuss whether an increase in the liability of the bank manager is suited to solve banks' incentive problems. In the policy discussion about bank manager compensation, the liability of the manager is a frequently raised issue. In fact, recent proposals, such as the deferral of bonuses or claw-back clauses, effectively raise bank manager liability. The general idea is that a manager who knows that he can lose part of his wealth will be more careful in his risk-taking decisions.

In this section, we derive three sets of results. First, we show that unlimited liability of the manager may have destabilizing effects. In fact, risk-taking incentives are exacerbated by unlimited liability, whereas the underinvestment in effort is mitigated. 
Second, we show that these results are weakened when we require the manager's compensation contract to satisfy monotonicity constraints. Third, the consequences of increasing manager liability depend on who determines the conditions under which the manager is made liable. If the shareholder sets the liability rules, he will use the manager's liability to fine-tune the contract, such that delegation costs decrease. This is detrimental for social welfare in some circumstances. If the government determines liability rules, the solution will be closer to the first-best, depending on the assumed scope of governmental intervention. To streamline the discussion, we consider the risk and effort choices separately. We focus on the economic arguments and move the formal discussion to the Appendix.

Unlimited liability of the manager. Assume that the manager has unlimited liability. Then $z_{h}, z_{m}$, and $z_{l}$ can be negative, in which case the manager has to pay a malus instead of receiving a bonus. The major difference to the setup with limited liability is that the manager can now be pushed to the participation constraint, reducing the manager's rents to the benefit of the shareholder. In both the risk and the effort model, the shareholder will make the manager pay in the medium outcome, $z_{m}<0$, to reduce the manager's rents.

In the risk model, the malus payment makes the medium outcome even less attractive, which increases risk-taking. In fact, equilibrium risk-taking is larger than with limited liability of the manager. The reason is that, under limited liability, the shareholder has to pay the manager a rent to make him take higher risk. With unlimited liability, the manager is kept at his participation constraint, making it cheaper for the shareholder to induce the manager to take risk. Consequently, unlimited liability exacerbates the risk-shifting problem.

In the effort model, the malus payment in the medium outcome again pushes the manager to the participation constraint, but without having any direct incentive effects. The shareholder does not make the manager liable in the low outcome because the manager's payment would benefit the bank's creditors, not the shareholder. Hence, the bonus scheme is again steeper than with limited liability: $z_{h}^{*}$ increases, and $z_{m}^{*}$ becomes negative. The reason is that it is now cheaper for the shareholder to induce the manager to exert effort. The equilibrium level of effort $e^{*}$ 
is also higher, and the bank's probability of default $p_{l}\left(e^{*}\right)$ drops. Hence, unlimited liability mitigates the underinvestment problem.

Summing up, increasing liability is useful only if managers put too little effort in administering their portfolio (if they are thought to be "lazy"). In that case, the underinvestment problem is mitigated and banks are stabilized because the shareholder can extract all rents from the manager, which makes it cheaper to induce effort. If, however, the problem is that managers take too much risk (and shareholders like them to do just that), an increase in the managers' liability backfires, managers take even more risk, and financial stability deteriorates. This contradicts the typical argument that bank managers will avoid risk-taking if their personal liability is increased.

Monotonicity of compensation contracts. The compensation contracts described in the previous paragraph have one peculiar property in equilibrium. Since $z_{l}^{*}=0$ and $z_{m}^{*}<0$, contracts are non-monotonic. Hence, the manager would like to let some money disappear in the medium outcome. Therefore, if the shareholder cannot observe the outcome directly, he has to implement a (weakly) monotonic bonus scheme with $z_{l} \leq z_{m} \leq z_{h}$. We will now show that the resulting contract will be such that the manager's choice is between that without liability and that with unlimited liability and unrestricted contracts. The argumentation is identical for risk and effort choices, so we present the argument for the risk model only.

Under the monotonicity requirement, the shareholder will set a contract with $z_{h} \geq 0$ and $z_{m}=z_{l} \leq 0$. Hence, the optimal contract will have identical malus payments for the medium and the low outcomes. In the medium outcome, the shareholder benefits from the malus payment. The equilibrium now depends on who benefits from the payment in the low outcome. If, hypothetically, payments benefited only the lenders, they would anticipate this payment and thus require a lower promised repayment $L$. Indirectly, the shareholder would again be the beneficiary of the malus payment. Although the contract has a different structure, the equilibrium risk choice $a^{*}$ would be the same as with unrestricted contracts. More realistically, the bail-out volume is reduced by the malus payment. Hence, the government is the beneficiary of the malus payment in the low outcome if a bail-out takes place (if not, the lenders benefit). From the viewpoint of the shareholder, the malus payment 
entails a positive externality on the government, and this externality is increasing in the (absolute value of the) malus payment. ${ }^{14}$ Consequently, in comparison to the situation where the lender is the only beneficiary, the shareholder will now implement a lower $z_{h}$ and less negative $z_{m}=z_{l}$. The equilibrium risk choice $a^{*}$ is smaller than with unrestricted contracts, but still larger than under limited liability. Arguments are the same for the effort choice, leading to an equilibrium effort $e^{*}$ that is smaller than with unrestricted contracts, but larger than under limited liability.

Summing up, even if the contract is required to be monotonic, an increase in manager liability is destabilizing in the risk model and beneficial in the effort model. The effects are, however, smaller than with unrestricted contracts.

Stipulation of liability rules by the government. The above results hinge on the fact that it is the shareholder who defines liability rules. Consider instead the situation where the welfare-maximizing government determines when the manager is made liable. The government will try to induce the manager to take less risk, or exert more effort, respectively. It will make the manager liable only in the low outcome, such that $z_{h}>0, z_{m}=0$, and $z_{l}<0$. If there were no legal restrictions and the manager had infinitely deep pockets, the government would set the malus payment such that it would retrieve the funds needed for bailing out the bank from the manager. That way, a maximum alignment of incentives would be achieved. In reality, this will not be possible, both due to legal restrictions and limited wealth of the manager. Therefore, maximum liability will be bounded. We can show, however, that an increase in the maximum liability of the manager will have the desired effects. Even if the shareholder reacts to some degree, risk-taking will be reduced in equilibrium and effort will be increased, relative to the situation without liability. Hence, if the government defines the conditions of the manager's liability, there will never be a backfiring effect.

Our overall conclusion is that an increase in manager liability may be harmful if managers are subject to a risk-shifting problem and the liability rules are set by the

\footnotetext{
${ }^{14}$ As long as the deposit insurance is not completely risk-sensitive, a similar externality would arise if the malus payment benefited the depositors or the deposit insurance.
} 
shareholder. In this situation, bonus caps are a more effective tool to limit risktaking. Manager liability is useful only if managers are subject to an effort problem, or if the liability rules are set by the government.

\subsection{The Role of Competition}

Finally, we consider the consequences of bank competition on the optimal policy regarding bonus restrictions. There are several markets on which banks compete. Let us discuss competition on the markets for deposits $\left(r_{d}\right)$, liabilities $\left(r_{l}\right)$, equity (the market for takeovers), and managers. Competition for deposits increases $r_{d}$, raising risk-shifting incentives. Condition (21) implies that more competition increases the range where a cap on bonuses is optimal. Competition for liabilities does not play a role directly, as $r_{l}$ does not appear in condition (21). The volume of liabilities weighted with the bail-out probability enters. Both for deposits and liabilities, the effect of competition on the respective risk-insensitive volumes is decisive. The market for takeovers does not seem to matter: irrespective of regulation, the shareholder always takes the optimal decision from the shareholder's perspective. Therefore, a takeover (or takeover threat) cannot improve corporate governance.

Now consider competition for managers. Especially in the presence of asymmetric information about the qualification of managers, bonuses can be a tool to attract high potentials (Bannier, Feess, and Packham, 2013). Banks (and other firms) offer contracts with bonuses, and high-type managers self-select into these contracts. That way, attracting high-type managers is cheaper than with flat contracts. A regulatory cap on bonuses for banks can then have negative effects. High-type managers can cheaply be poached by non-banks, maybe even by financial institutions from the unregulated shadow banking sector. The aggregate welfare effect depends crucially on what "high type" and "low type" stands for. If "high type" means that it is easy for the manager to shift risk (low $\alpha$ ), then poaching the high-type managers away from the banking sector may even increase welfare. If "high type" means that the manager can increase the project's NPV without much effort (low $\eta)$, then poaching the high-type managers away from the banking sector can be detrimental. ${ }^{15}$

\footnotetext{
${ }^{15}$ We abstract from dynamic aspects in our model. Acharya, Pagano, and Volpin (2013) show
} 
Summing up, higher competition in the deposit (and lending) market raises the desirability of bonus caps because it affects the gains from risk-shifting. Competition for managers may push "high-type" bank managers to other sector, which may or may not be desirable, depending on the definition of types.

\section{Conclusion}

In this paper, we have shown that bonus contracts may arise endogenously as a response to agency problems within banks. If there is a risk-shifting problem, the shareholder designs a bonus scheme that induces the bank manager to take excessive risk. Alternatively, bank bonuses can be used to incentivize the manager to take effort. Since the shareholder does not fully internalize the benefits of higher effort, there is an underinvestment problem.

The anticipation of a bail-out weakens market discipline and induces the shareholder to steepen the bonus scheme in the risk-shifting setup, exacerbating the risk-shifting problem. In the effort model, anticipated bail-outs flatten the bonus scheme, reducing effort even further. In either setup, bail-outs are harmful and raise a bank's probability of default. When both types of agency problems are present, the effect of anticipated bail-outs on bonus schemes is ambiguous, depending on the relative importance of the risk-shifting and the effort problem.

Regulatory caps on bonuses are a way to mitigate the risk-shifting problem. However, this comes at the cost of reducing managers' incentives to exert effort. But especially if bail-out expectations are strong, the risk-shifting problem always dominates the effort problem, leading to excessively high bonus payments. At the same time, alternative instruments, such as risk-sensitive deposit insurance are less effective when bail-out expectations are high. This yields a rationale for regulatory bonus restrictions.

Interestingly, unlimited liability of the manager may be counterproductive, both from a welfare and a stability perspective. While it helps to mitigate the effort

that bank manager compensation based on short-term performance (leading to excessive risktaking) may arise endogenously if there is competition for managers. Such aspects cannot be studied in our static setup. 
problem, it exacerbates the risk-shifting problem. Therefore, raising managers' liability may not be desirable. A stronger alignment of interests between shareholders and managers destabilizes banks if shareholders have strong risk-taking incentives.

The model enables us to evaluate recent reform proposals by the Financial Stability Board, which have become an integral part of the G20 recommendations (see Financial Stability Board, 2009). The most important suggestions are the enforced deferral of a significant portion of variable compensation to reward long-term success rather than short-term risk-taking; the introduction of claw-back clauses to make sure that money can be recouped if decisions turn bad later on; the payment of bonuses in stock options rather than cash; greater transparency; the establishment of a board remuneration committee to oversee compensation schemes on behalf of the board of directors; and finally, supervisory review of compensation structures. This list reveals that the main concern is an increase in bank managers' liability, which is believed to better align the incentives between managers and shareholders (for an early statement of this view, see Macey and O'Hara, 2001). Outright bonus ceilings are not part of the G20 recommendations.

In fact, many countries have already started to implement a regulation of bank manager compensation, along the lines of the G20 proposals. In Europe, immediate cash bonuses are restricted to 20 to 30 percent; the remaining bonus payment has to be deferred, with at least 50 percent to be paid in stocks. However, there are no size limitations on bonus payments. In the United States, regulation is expected to prescribe a deferral of only 50 percent, with a restriction of 20 percent on immediate cash bonuses. In addition, several countries, such as Germany and the United States, have introduced absolute compensation ceilings for managers at banks that benefited from government bail-outs. The United Kingdom introduced an ex-post tax on bonuses exceeding a certain amount.

Our analysis supports the view that ceilings on bonus payments are appropriate to prevent excessive risk-taking. This is especially true for SIFIs (systemically important financial institutions), for which (implicit) bail-out guarantees - and thus risk-shifting incentives - are strongest, for banks with many non-traditional banking activities, and for banks in countries with weak regulatory frameworks and without credible resolution procedures. In contrast, we show that an increase in bank managers' liability may backfire and raise risk-taking rather than curbing it. Therefore, 
measures increasing managers' liability, such as a deferral of bonuses and claw-back clauses, are questionable. Moreover, a better alignment of managers' and shareholders' interests does not solve the problem if the dominant agency problem is between the bank and the deposit insurance or the taxpayer. If it is in the shareholders' interest to take higher risks, an alignment of interests does not help. The only G20 recommendation, which is broadly in line with the implications of our model, is the introduction of a supervisory review of compensation structures, which comes close to the idea of the government determining liability rules.

In the crisis, several countries introduced strict bonus caps only on banks that were bailed out. While this may be justified on grounds of fairness, efficiency considerations suggest that caps should be imposed on all banks with sufficiently high bail-out probabilities. These may well be banks that were not bailed out in the recent crisis. Moreover, the optimality of bonus caps was shown to depend on bank-specific parameters in our model, implying that one size may not fit all. More specifically, our paper supports caps on bonus payments especially for systemically important financial institutions (SIFIs), for which (implicit) bail-out guarantees are strongest, and for banks with a high share of non-traditional banking activities. Taxes on bonuses can achieve the same result as bonus caps, but not if they are imposed ex post on a one-time basis, as in the United Kingdom. With permanently higher bailout perceptions, caps should not be lifted after the crisis, unless a new regulatory framework is able to curb bail-out expectations. At the moment, this seems unlikely. 


\section{A Proofs}

Proof of Proposition 1: The first two points are proven in the main text. The increase in the manager's expected (monetary) compensation, $p_{h} z_{h}$, follows directly from the rise in $p_{h}$ (due to the rise in $a^{*}$ ) and the rise in $z_{h}^{*}$. The manager's expected profit (net of the non-monetary cost) is

$$
\Pi_{M}=z_{h}^{*}\left(p_{h}^{0}+\frac{z_{h}^{*}}{2 \alpha Y_{h}^{2}\left(Y_{h}-Y_{m}\right)^{2}}\right),
$$

which also increases in $z_{h}^{*}$, and hence in $\beta$.

Proof of Proposition 2: From (12) and (13), it is apparent that $d z_{h}^{*} / d \beta<0$ and $d e^{*} / d \beta<0$, which proves the first two statements. The manager's expected compensation $p_{h} z_{h}$ decreases in $\beta$ because $p_{h}$ decreases (due to the drop in $e^{*}$ ) and $z_{h}^{*}$ decreases. The manager's expected profit

$$
\Pi_{M}=z_{h}^{*}\left(p_{h}^{0}+\frac{z_{h}^{*}}{2 \eta}\right)
$$

increases in $z_{h}^{*}$, which decreases in $\beta$.

Proof of Proposition 3: The first statement has been shown in the main text. The manager's equilibrium choices are given by (15), so both $a^{*}$ and $e^{*}$ increase in $z_{h}$. Hence, they increase in $\beta$ if and only if $z_{h}$ increases in $\beta$, which is true if (18) holds. Inserting equilibrium values into $p_{l}$ and taking the derivative with respect to $\beta$ yields

$$
\frac{\mathrm{d} p_{l}}{\mathrm{~d} \beta}=\frac{\left(\eta / \alpha-Y_{h}^{2} Y_{m}\left(Y_{h}-Y_{m}\right)\right)^{2}}{2 \eta Y_{h}^{2} Y_{m}^{2}\left(\eta / \alpha+Y_{h}^{2}\left(Y_{h}-Y_{m}\right)^{2}\right)},
$$

which is positive. For the third point, look at the manager's expected compensation and expected profit,

$$
\begin{aligned}
p_{h} z_{h}^{*} & =z_{h}^{*}\left(p_{h}^{0}+z_{h}^{*}\left(\frac{1}{\eta}+\frac{1}{\alpha Y_{h}^{2}\left(Y_{h}-Y_{m}\right)^{2}}\right)\right) \\
\Pi_{M} & =z_{h}^{*}\left(p_{h}^{0}+\frac{z_{h}^{*}}{2}\left(\frac{1}{\eta}+\frac{1}{\alpha Y_{h}^{2}\left(Y_{h}-Y_{m}\right)^{2}}\right)\right) .
\end{aligned}
$$

Both increase in $z_{h}^{*}$.

Proof of Proposition 4: This is a direct consequence of condition (21). 
Proofs for Section 6.3: First, consider the risk-choice setting with unlimited liability. We have argued that $z_{h}>0, z_{m}<0$ and $z_{l}=0$. The problem is again solved by backward induction. The manager now maximizes

$$
\begin{aligned}
\Pi_{M} & =\left(p_{h}^{0}+\frac{a}{Y_{h}\left(Y_{h}-Y_{m}\right)}\right) z_{h}+\left(p_{m}^{0}-\frac{a}{Y_{m}\left(Y_{h}-Y_{m}\right)}\right) z_{m}-\alpha \frac{a^{2}}{2} \\
\Longrightarrow a^{*} & =\frac{Y_{m} z_{h}-Y_{h} z_{m}}{Y_{h} Y_{m}\left(Y_{h}-Y_{m}\right) \alpha} .
\end{aligned}
$$

A higher payment in the high outcome $\left(z_{h}\right)$ raises risk-taking, whereas a higher payment in the medium outcome $\left(z_{m}\right)$ lowers risk-taking. For $L$ and $D$, we obtain the same expression as in (4) and (5). The shareholder maximizes

$$
\Pi_{E}=p_{h}\left(a^{*}\right)\left(Y_{h}-D-L-z_{h}\right)+p_{m}\left(a^{*}\right)\left(Y_{m}-D-L-z_{m}\right)
$$

subject to the manager's participation constraint, $\Pi_{M} \geq 0$, and with $a^{*}$ being given by (30). The participation constraint is binding in equilibrium, yielding a relation between $z_{h}$ and $z_{m}$. This is the major difference to the setup with limited liability, where the manager could not be pushed to the participation constraint. The firstorder conditions yield the solutions

$$
\begin{aligned}
& z_{h}^{*}=\frac{\beta l+\left(1+r_{d}\right) d}{p_{h}^{0} Y_{h}+p_{m}^{0} Y_{m}}\left(p_{m}^{0}\left(Y_{h}-Y_{m}\right)-\frac{\beta l+\left(1+r_{d}\right) d}{2 \alpha Y_{h} Y_{m}^{2}}\right), \\
& z_{m}^{*}=-\frac{\beta l+\left(1+r_{d}\right) d}{p_{h}^{0} Y_{h}+p_{m}^{0} Y_{m}}\left(p_{h}^{0}\left(Y_{h}-Y_{m}\right)-\frac{\beta l+\left(1+r_{d}\right) d}{2 \alpha Y_{h}^{2} Y_{m}}\right) .
\end{aligned}
$$

Some algebra shows that $z_{h}^{*}>0$ and $z_{m}^{*}<0$ as long as probabilities are positive. Hence, the interior solution always applies, the zero-bonus contract is never optimal. Plugging (32) and (33) into (30), we obtain the equilibrium values of $a^{*}$ and $p_{l}\left(a^{*}\right)$,

$$
\begin{aligned}
a^{*} & =\frac{\beta l+\left(1+r_{d}\right) d}{\alpha Y_{h} Y_{m}}, \\
p_{l}\left(a^{*}\right) & =1-p_{h}^{0}-p_{m}^{0}+\frac{\beta l+\left(1+r_{d}\right) d}{\alpha Y_{h}^{2} Y_{m}^{2}} .
\end{aligned}
$$

Risk-shifting is always positive, and especially it is always larger than under limited liability, see (9).

Now consider the effort-choice setting with unlimited liability. Again, $z_{h}^{*}>0, z_{m}^{*}<0$ and $z_{l}^{*}=0$. The manager's optimization problem and effort choice are

$$
\begin{aligned}
\Pi_{M} & =p_{h}(e) z_{h}+p_{m}(e) z_{m}-\eta e^{2} / 2, \\
e^{*} & =z_{h} / \eta .
\end{aligned}
$$


The shareholder's optimization problem and equilibrium contract choice are

$$
\begin{aligned}
\Pi_{E} & =p_{h}\left(e^{*}\right)\left(Y_{h}-D-L-z_{h}\right)+p_{m}\left(e^{*}\right)\left(Y_{m}-D-L-z_{m}\right), \\
z_{h}^{*} & =Y_{h}-\beta l-\left(1+r_{d}\right) d, \\
z_{m}^{*} & =-\frac{\left(Y_{h}-\beta l-\left(1+r_{d}\right) d\right)\left(Y_{h}-\beta l-\left(1+r_{d}\right) d\right)+2 \eta p_{h}^{0}}{2 \eta p_{m}^{0}},
\end{aligned}
$$

which leads to an effort of

$$
e^{*}=\frac{Y_{h}-\beta l-\left(1+t_{d}\right) d}{\eta}
$$

and a probability of the low outcome of

$$
p_{l}=1-p_{h}^{0}-p_{m}^{0}-\frac{Y_{h}-\beta l-\left(1+r_{d}\right) d}{\eta} .
$$

Effort is higher than under limited liability, hence the probability of default is smaller.

Now consider the risk-choice setting with monotonic bonus contracts. Bonus payments are $z_{h}$ and $z_{m l}:=z_{m}=z_{l}$. The manager maximizes

$$
\begin{aligned}
\Pi_{M} & =p_{h}(a) z_{h}+p_{m}(a) z_{m l}+p_{l}(a) z_{m l}-\alpha \frac{a^{2}}{2} \\
\Longrightarrow a^{*} & =\frac{z_{h}-z_{m l}}{Y_{h}\left(Y_{h}-Y_{m}\right) \alpha} .
\end{aligned}
$$

In the high outcome, the shareholder pays the bonus, in the medium outcome, he benefits from the manager's liability. In the low outcome, he does not benefit directly. For the sake of the argument, let us first assume that only lenders benefit. Their breakeven condition then becomes

$$
\left[p_{h}(a)+p_{m}(a)\right] L+p_{l}(a) \beta l+p_{l}(a) z_{m l}=\left(1+r_{l}\right) l
$$

The shareholder then maximizes his expected profit,

$$
\Pi_{E}=p_{h}\left(a^{*}\right)\left(Y_{h}-D-L-z_{h}\right)+p_{m}\left(a^{*}\right)\left(Y_{m}-D-L-z_{m l}\right) .
$$

The ensuing optimal contract has

$$
\begin{aligned}
z_{h}^{*} & =\frac{\beta l+\left(1+r_{d}\right) d}{Y_{m}}\left(\left(1-p_{h}^{0}\right)\left(Y_{h}-Y_{m}\right)-\frac{\beta l+\left(1+r_{d}\right) d}{2 \alpha Y_{h}^{2} Y_{m}}\right), \\
z_{m l}^{*} & =-\frac{\beta l+\left(1+r_{d}\right) d}{Y_{m}}\left(p_{h}^{0}\left(Y_{h}-Y_{m}\right)+\frac{\beta l+\left(1+r_{d}\right) d}{2 \alpha Y_{h}^{2} Y_{m}}\right) .
\end{aligned}
$$


The corresponding probability of the low outcome is exactly as in (35). Consequently, if part of $z_{m l}$ does not go to lenders in the low outcome, the marginal cost of inducing the manager to take risk increases. Consequently, the shareholder will implement a flatter contract with smaller $z_{h}^{*}$ and smaller absolute $\left|z_{m l}^{*}\right|$. The manager will thus take less risk. The equilibrium amount of risk will be larger than in the limited-liability case. The reason is that any malus $z_{m l}^{*}$ will push the manager to increase risk, even if $z_{h}^{*}$ also reacts.

Now consider the effort-choice setting with monotonic bonus contracts. Bonus payments are $z_{h}$ and $z_{m l}=z_{m}=z_{l}$. The manager's maximization problem and solution become

$$
\begin{aligned}
\Pi_{M} & =p_{h}(e) z_{h}+p_{m}(e) z_{m l}+p_{l}(e) z_{m l}-\eta e^{2} / 2, \\
e^{*} & =\frac{z_{h}-z_{m l}}{\eta}
\end{aligned}
$$

Maximizing the shareholder's profit function yields

$$
\begin{gathered}
z_{h}^{*}=\left(Y_{h}-\beta l-\left(1+r_{d}\right) d\right)\left(1-p_{h}^{0}-\frac{Y_{h}-\beta l-\left(1+r_{d}\right) d}{2 \eta}\right), \\
z_{m l}^{*}=-\left(Y_{h}-\beta l-\left(1+r_{d}\right) d\right)\left(p_{h}^{0}+\frac{Y_{h}-\beta l-\left(1+r_{d}\right) d}{2 \eta}\right) .
\end{gathered}
$$

If only the lender benefits from $z_{m l}$, the equilibrium effort choice is as in (38). Again, if part of $z_{m l}$ does not go to lenders in the low outcome, the shareholder will implement a flatter contract with smaller bonus $z_{h}$ and smaller absolute $\left|z_{m l}^{*}\right|$. This results in less effort.

Now consider the risk-choice setting with the government stipulating the liability rules. If the government forces the manager to pay a malus $z_{l}$ in the low outcome, the manager's problem becomes

$$
\begin{aligned}
\Pi_{M} & =p_{h}(a) z_{h}+p_{l}(a) z_{l}-\alpha \frac{a^{2}}{2} \\
\Longrightarrow a^{*} & =\frac{z_{h} Y_{m}+z_{l}\left(Y_{h}-Y_{m}\right)}{\alpha Y_{h}\left(Y_{h}-Y_{m}\right) Y_{m}} .
\end{aligned}
$$

The shareholder maximizes his profits and chooses the contract

$$
z_{h}^{*}=\left.z_{h}^{*}\right|_{z_{l}=0}-\frac{Y_{h}-Y_{m}}{2 Y_{m}} z_{l} .
$$


Remember that $z_{l}<0$, hence if $\left|z_{l}\right|$ increases, the bonus $z_{h}^{*}$ also increases. The ensuing probability of the low outcome is

$$
p_{l}=\left.p_{l}\right|_{z_{l}=0}+\frac{1}{2 \alpha Y_{h}^{2} Y_{m}^{2}} z_{l}
$$

A larger malus payment (i. e., higher liability in the low outcome) implies lower default risk.

Finally, consider the effort-choice setting with the government stipulating the liability rules. The manager's effort choice is $e^{*}=\left(z_{h}-z_{l}\right) / \eta$. Following the same procedure as above, we get

$$
\begin{aligned}
& z_{h}^{*}=\left.z_{h}^{*}\right|_{z_{l}=0}+\frac{z_{l}}{2} \text { and } \\
& p_{l}=\left.p_{l}\right|_{z_{l}=0}+\frac{z_{l}}{2 \eta} .
\end{aligned}
$$

Again a higher malus payment leads to lower default risk. 


\section{References}

Acharya, V. V., M. Pagano, and P. F. Volpin (2013): "Seeking Alpha: Excess Risk Taking and Competition for Managerial Talent," Unpublished Working Paper.

Bannier, C. E., E. Feess, and N. Packham (2013): "Competition, Bonuses, and Risk-Taking in the Banking Industry," Review of Finance, forthcoming.

Bebchuk, L. A., A. Cohen, and H. Spamann (2010): "The Wages of Failure: Executive Compensation at Bear Stearns and Lehman 2000- 2008," Yale Journal on Regulation, 27, 257-282.

Becht, M., P. Bolton, And A. Röell (2003): "Corporate Governance and Control," in Handbook of the Economics of Finance, pp. 1-109. Elsevier.

Biais, B., and C. Casamatta (1999): "Optimal Leverage and Aggregate Investment," Journal of Finance, 54(4), 1291-1323.

Caprio, G., and R. Levine (2002): "Corporate Governance in Finance: Concepts and International Observations," in Financial Sector Governance: The Roles of the Public and Private Sectors, pp. 17-50. Brookings Institution Press, Washington, DC.

Cheng, I.-H., H. G. Hong, and J. A. Scheinkman (2010): "Yesterday's Heroes: Compensation and Creative Risk-Taking," ECGI - Finance Working Paper No. $285 / 2010$.

Chesney, M., J. Stromberg, and A. F. Wagner (2010): "Risk-Taking Incentives, Governance, and Losses in the Financial Crisis," Swiss Finance Institute Research Paper Series No. 10-18.

DemirgüÇ-Kunt, A., And H. Huizinga (2004): "Deposit Insurance and Market Discipline," Journal of Monetary Economics, 51(2), 375-399.

Fahlenbrach, R., And R. Stulz (2011): "Bank CEO Incentives and the Credit Crisis," Journal of Financial Economics, 99(1), 11-26.

Financial Stability Board (2009): "FSB Principles for Sound Compensation Practices - Implementation Standards," Discussion paper. 
Freixas, X., And J.-C. Rochet (2013): "Taming SIFIs," Journal of Money, Credit and Banking, forthcoming.

Gropp, R., H. Hakenes, and I. Schnabel (2011): "Competition, Risk-Shifting, and Public Bail-out Guarantees," Review of Financial Studies, 24(6), 2084-2120.

Gropp, R., And M. Köhler (2010): "Bank Owners or Bank Managers: Who is Keen on Risk? Evidence from the Financial Crisis," European Business School Research Paper Series No. 10-02.

Houston, J. F., And C. James (1995): "CEO Compensation and Bank Risk: Is Compensation in Banking Structured to Promote Risk Taking?," Journal of Monetary Economics, 36(2), 405-431.

John, K., And T. A. John (1993): “Top-Management Compensation and Capital Structure," Journal of Finance, Papers and Proceedings, 48(3), 949-974.

John, K., H. Mehran, And Y. QIAn (2010): "Outside Monitoring and CEO Compensation in the Banking Industry," Journal of Corporate Finance, 16(4), 383-399.

John, K., A. Saunders, And L. W. Senbet (2000): "A Theory of Banking Regulation and Management Compensation," Review of Financial Studies, 13(1), $95-125$.

Laeven, L., And R. Levine (2009): "Bank Governance, Regulation, and Risk Taking," Journal of Financial Economics, 93(2), 259-275.

Macey, J. R., And M. O'Hara (2001): "The Corporate Governance of Banks," FRBNY Economic Policy Review, April, 91-107.

Prendergast, C. J. (1999): "The Provision of Incentives in Firms," Journal of Economic Literature, 37(1), 7-63.

Shleifer, A., And R. W. Vishny (1997): "A Survey of Corporate Governance," Journal of Finance, 52(2), 737-783. 